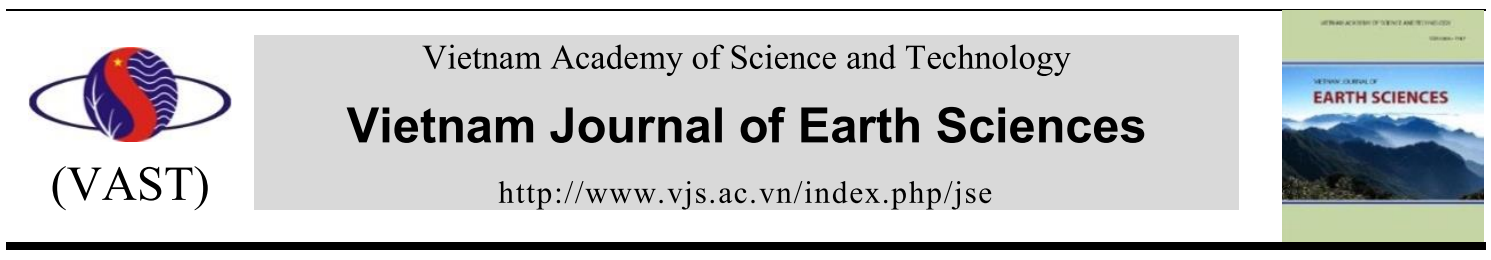

\title{
Variability of sea surface chlorophyll_a concentration in the South Vietnam coastal waters related to enso phenomenon
}

\author{
Vu Van Tac \\ Institute of Oceanography, VAST, Nha Trang, Vietnam
}

Received 26 February 2019; Received in revised form 26 October 2019; Accepted 17 December 2019

\begin{abstract}
This paper focuses on analyzing the monthly averaged sea surface chlorophyll_a concentration data for 16 years (Jul. $2002 \div$ Sep. 2018), a remote sensing data product of the US National Aeronautics and Space Administration (US NASA), the analyzed results have shown that each occurrence of ENSO phenomenon greatly affects the fluctuation of chlorophyll_a concentration in the South Vietnam's coastal waters (SVNC). The monthly averaged chlorophyll_a concentration varies from $0.5\left[\mathrm{mg} / \mathrm{m}^{3}\right]$ to $1.1\left[\mathrm{mg} / \mathrm{m}^{3}\right]$ (equivalent to $22.4 \% \div 49.3 \%$ ), while the monthly averaged fluctuation of chlorophyll_a concentration between months is only $0.22\left[\mathrm{mg} / \mathrm{m}^{3}\right]$ (equivalent to $9.88 \%$ ). These fluctuations have a great impact on nutritional resources as well as water quality because chlorophyll_a is a pigment in plankton, which is a criterion to assess the "rich or poor" of nutrition source in seawater. The results of this study are considered as a "small piece" in the overall picture of the impact of ENSO phenomenon on global climate change.
\end{abstract}

Keywords: The South Vietnam's coastal waters; Sea surface chlorophyll_a; chlorophyll_a anomaly; MODIS; ENSO.

C2020 Vietnam Academy of Science and Technology

\section{Introduction}

Global climate change poses major threats to human survival. Nowadays, more and more frequent and intense drought, storms, heatwaves, rising sea levels, melting glaciers and warming oceans can directly harm animals, destroy the places they live, and wreak havoc on people's livelihoods and communities. During the United Nations Conference on Climate Change (COP 23) taking place in Bonn (Germany) in November 2017 , there was a report that attracted special attention from scientists. It is a report on

"Corresponding author, Email: quiet_seavn@yahoo.com
Global Climate Risk Index (David et al., 2017). The report shows the increasing consequences of climate change otherwise the situation will be more difficult to control. Notably, Vietnam ranks fifth among the most severely affected countries by climate change. The report is also particularly concerned when countries such as India, Sri Lanka and Vietnam are constantly suffering from irregular weather and do not have enough time to overcome the consequences. Vietnam is among the countries seriously affected by natural disasters and floods. Climate change threatens urban infrastructure and the quality of life of people, especially coastal areas. The report also summarized in 10 years from 1997 
to 2016, natural disasters claimed the lives of 520,000 people and caused economic losses of up to 316 trillion USD.

In climate anomaly studies, scientists paid special attention to ENSO (El Niño-Southern Oscillation) phenomenon. The ENSO is a naturally occurring phenomenon that involves fluctuation of ocean temperature in the central and eastern equatorial Pacific, coupled with changes in the atmosphere (WMO, 2014). This phenomenon refers to the cycle of warm and cold temperatures, as measured by sea surface temperature (SST) of the tropical central and eastern Pacific Ocean. This cycle can be divided into three phases in which there are two opposing phases: El Niño and La Niña, the phase in between these two phases is called Neutral. The El Niño indicates an unusual increase in the temperature of the equatorial waters of the eastern Pacific Ocean spreading from the equator, along to the coast of Peru and Ecuador to the south. This warm water often reached the strongest intensity on Christmas holidays (U.S. National Research Council, 1996), also known as ENSO's warm phase. La Niña is the reverse process, also known as ENSO's cold phase. The ENSO phenomenon is related to the fluctuation of atmospheric pressure between the two eastern banks of the Pacific Ocean and the Eastern Indian Ocean (known as the Southern Oscillation to distinguish it from the pressure fluctuations in the North Atlantic). Vietnam is in the western equator of the Pacific Ocean, is the area affected by ENSO. Many studies have shown the social-economic impacts of ENSO on human. Marine phytoplankton plays a vital role in the global carbon cycle via photosynthetic carbon fixation and produces nearly half of the world's oxygen via photosynthesis. Every time ENSO phenomenon occurs, climate and weather change abnormally, causing droughts, floods and natural disasters in many different regions of the world (Dilley et al., 1995; Ward et al., 2006).

The influence scope of ENSO phenomenon is global (Domeisen et al., 2019), however, each region is subject to different influences depending on location and terrain. Even in different regions of Vietnam are subject to different effects of ENSO phenomenon.

The chlorophyll_a, found in microscopic plant phytoplankton, is known to produce systematic variations in the color of the ocean. In open ocean waters, ocean color is used as an indicator of chlorophyll_a concentration, so the presence of chlorophyll_a considered to be a predictor of ocean health. That is why nowadays sea surface chlorophyll_a concentration is commonly used in primary productivity research as well as water quality monitoring.

The studies of variability of chlorophyll_a associated with ENSO phenomenon have also received much attention in the world. Based on images from various satellite sensors, spatial and temporal statistics of the surface temperature and chlorophyll fronts in the California Current showed the trend, when sea surface temperature decreases, chlorophyll content increases (Kahru et al., 2012). The study of abnormal upwelling and chlorophyll_a concentration off South Vietnam in summer 2007 (Liu et al., 2012), showed that at the time of calculation, the strengthening southwest monsoon was considered as an important factor in promoting the strong upwelling and concurrent phytoplankton blooming off the South Vietnam coast, making the sea surface temperature decrease and the chlorophyll_a concentration increase. The analysis of the impact of ENSO on the regional chlorophyll-a anomaly in the Papua waters is found that when El Niño events occur the negative SST anomaly in the Papua waters as well as the enhanced upwelling cause the increase of 
chlorophyll-a concentration (Dewi et al., 2018).

In Vietnam, there have been many studies related to ENSO phenomenon so far. The analysis of effects of ENSO on autumn rainfall in Central Vietnam shows that total fall rainfall is reduced by $10-30 \%$ in the $\mathrm{El}$ Niño years but increased by $9-19 \%$ in the $\mathrm{La}$ Niña years (Vu et al., 2005). The study of abnormal features of oceanographic characteristics in upwelling Vietnam waters under impacting of El Niño events (Tong et al., 2017) has partly clarified the impact of ElNiño phenomenon on the occurrence time and position of the center of the upwelling Vietnam waters. Another notable analysis is the analyzing sea surface chlorophyll concentration data in Vietnam South Central Coast from MODIS satellite images (Vu et al., 2018). The analysis results showed that there is not obvious difference of the chlorophyll anomaly index between El Niño and neutral years. However, in La Niña years the chlorophyll anomaly index is greatly varied and generally inversely proportional to the Oceanic Niño Index (ONI), which means chlorophyll anomaly index rose while ONI fell. This impact has made chlorophyll in the summer and autumn of La Niña years higher by $0.22 \div 0.38\left[\mathrm{mg} / \mathrm{m}^{3}\right]$ in comparison with other years. etc.

In this paper, we analyze "variability of sea surface chlorophyll_a concentration in the South Vietnam's coastal waters (SVNC) related to ENSO phenomenon through ONI" to find out the characteristics, cycle and variability of sea surface chlorophyll_a concentration in the SVNC, contributing to improving the understanding of the impact of climate change abnormalities in the study area, supporting scientists and managers in proposing measures to prevent, avoid efficiently, limit and mitigate the damage caused by ENSO, and having reasonable alternatives in the protection of biodiversity as well as environment in the SVNC.

\section{Materials, study area and methods}

\subsection{Materials}

In this study, the data was collected and processed including:

- Monthly mean sea surface chlorophyll-a concentration data was extracted from the Level-3 Product Suite of the Aqua MODIS with a spatial resolution of $4 \times 4 \mathrm{~km}^{2}$ for 16 years (Jul. 2002 $\div$ Sep. 2018). This data was estimated by applying the Ocean Chlorophyll MODIS OCx algorithm and was obtain from The National Aeronautics and Space Administration (NASA) Ocean Color website (https://oceancolor.gsfc.nasa.gov/)(NASA

Goddard Space Flight Center, 2018). This is a remote dataset from the NASA Ocean Biology Processing Group (OBPG). The OBPG is the official NASA data center that archives and distributes ocean color data. In particular, this data dataset ensures spatial synchronization and is long enough to cover the cycles of the ENSO phenomenon.

- One minute gridded bathymetric dataset is extracted from the GEBCO software of the British Oceanographic Data Centre. The dataset includes bathymetric and the boundary of Southeast Asia Sea, which are used to determine the study area (Fig. 1).

- The Oceanic Niño Index (ONI) data table of National Oceanic and Atmospheric Administration (NOAA), get archived in the Golden Gate Weather Services (http://ggweather.com/enso/oni.htm). The ONI is a measure of the departure from normal sea surface temperature in the east-central Pacific Ocean, is the standard means by which each El Niño episode is determined, gauged, and forecast. El Niño episodes are indicated by sea surface temperature increases of more than $0.5^{\circ} \mathrm{C}$ and La Niña episodes are indicated by sea surface temperature decreases of more than $0.5^{\circ} \mathrm{C}$ for at least five successive overlapping threemonth seasons. Nowadays, the ONI has become the de-facto standard that NOAA uses for identifying El Niño and La Niña events in the tropical Pacific. 


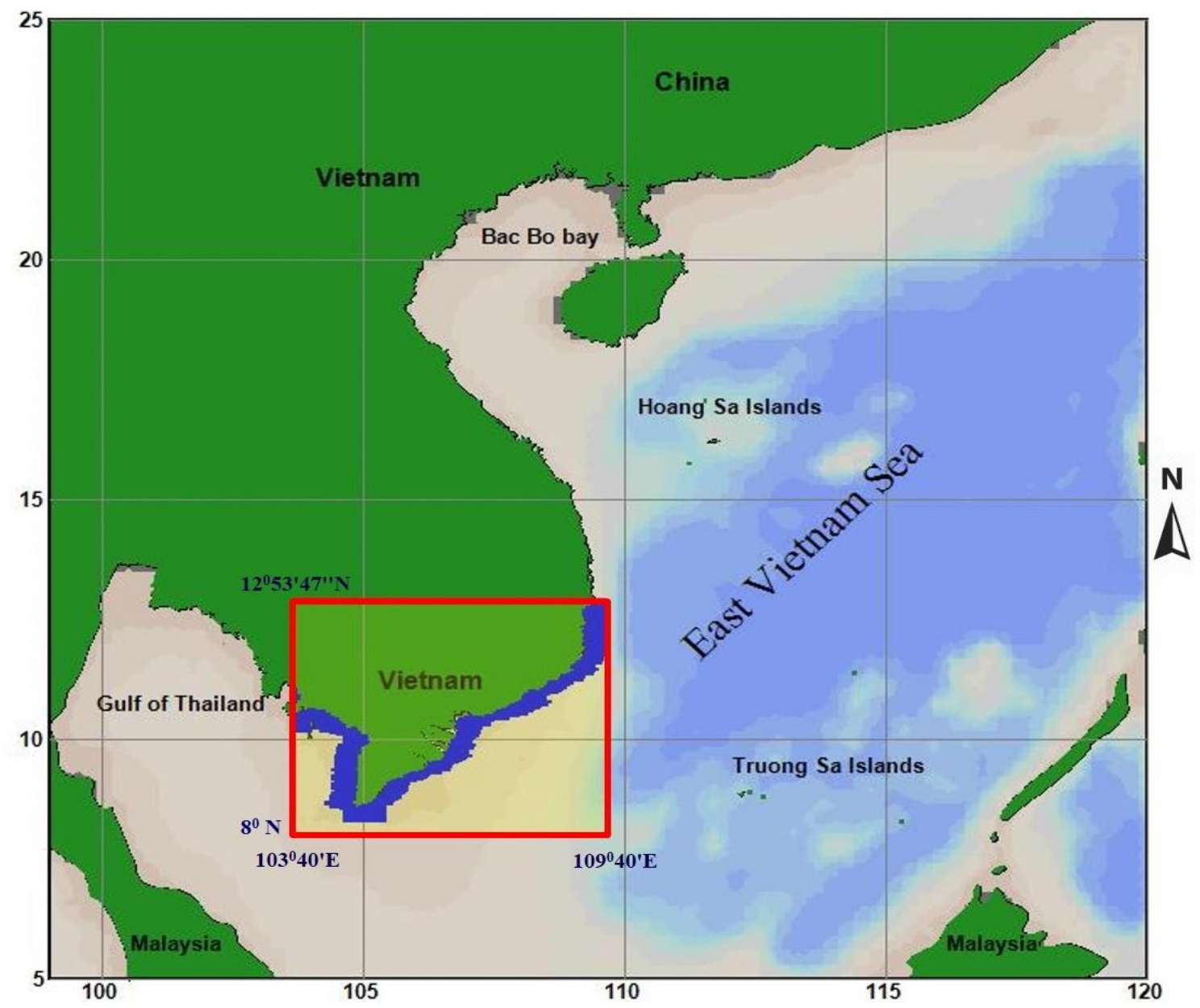

Figure 1. The study area and the spatial distribution of chlorophyll_a value points

\subsection{Study area}

Based upon geology, topography, weather characteristics and interaction between the continent and the sea, the Vietnamese coast is divided into three separate regions: The North, the Central and the South (Tran, 2015). In preliminary analysis of MODIS Aqua data, we found that in some months, due to the very bad weather conditions in the North and Central waters of Vietnam, there are so many blank values in the image data. However, it has very good estimated values in the SVNC. Therefore, in this study, we got the latitude $12^{\circ} 53^{\prime} 47^{\prime \prime} \mathrm{N}$ (the latitude passing through Dai Lanh cape, Phu Yen province) to limit the study area to be the SVNC, limited from longitude $103^{\circ} 40^{\prime} \mathrm{E}$ to $109^{\circ} 40^{\prime} \mathrm{E}$ and latitude from $8^{\circ} \mathrm{N}$ to $12^{\circ} 53^{\prime} 47^{\prime \prime} \mathrm{N}$. The SVNC are limited from Dai Lanh cape to Ha Tien (Kien Giang Province), is the place where interaction between the land of Southern Vietnam with the sub-equatorial monsoon, and the marine part of South zone in the East Sea with sub-equatorial monsoon occurs (Tran, 2015). In addition, in the study area, calculations only focuse on coastal points limited to distances from $0 \div 40 \mathrm{~km}$ far from the shore. This area is directly affected by the continent through river systems and the local climate. The study area and the spatial distribution of chlorophyll_a value points are described in Fig. 1. 


\subsection{Methods}

The study data source consists of 195 netCDF files corresponding to 195 months $(07 / 2002 \div 9 / 2018)$, which were downloaded from the NASA Ocean Color website. In each of these files is stored the monthly sea-surface chlorophyll_a concentration $\left(\mathrm{mg} / \mathrm{m}^{3}\right)$ for the global scope. Figure 2 illustrates some netCDF level 3 files on the NASA Ocean Color
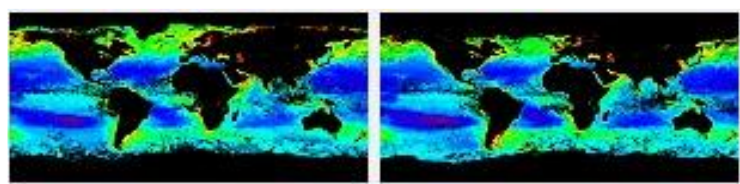

September 2002

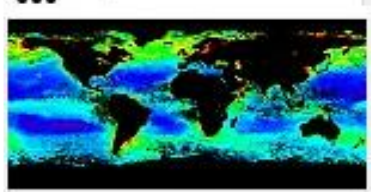

September 2003

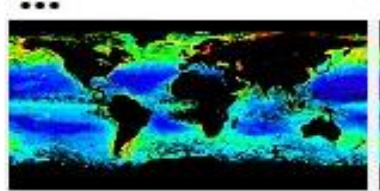

September 2008

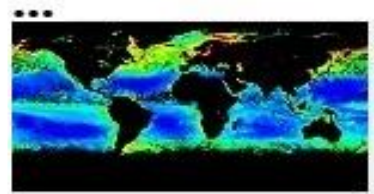

May 2010

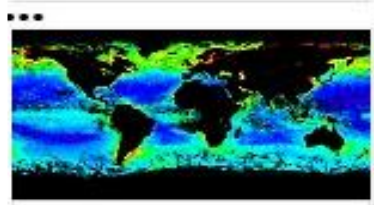

September 2012

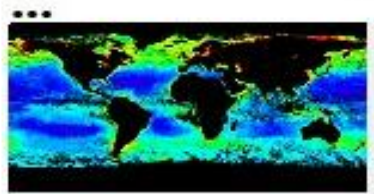

September 2015
October 2002

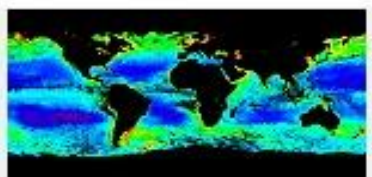

October 2003

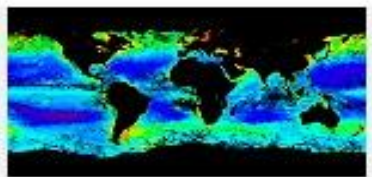

October 2008

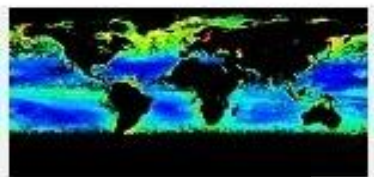

June 2010

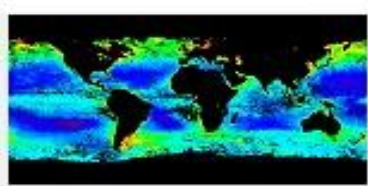

October 2012

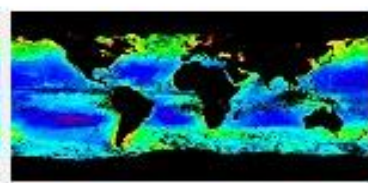

October 2015 website. We used the HDF Viewer software to extract chlorophyll_a data from these files to text files for the study area, and then collected all of these chlorophyll_a data into a table in an Access database. This table contains 4 fields: Date; Longitude, latitude, and chlorophyll_a concentration $\left(\mathrm{mg} / \mathrm{m}^{3}\right)$. From the table, we implement data quality control and statistical calculations for the study.

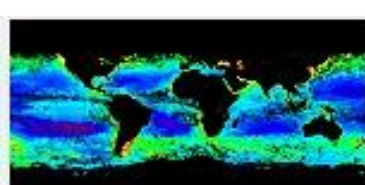

November 2002

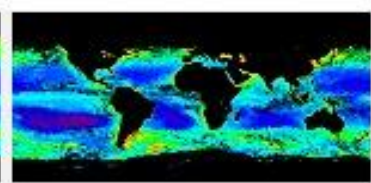

November 2003

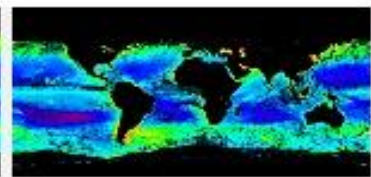

November 2008

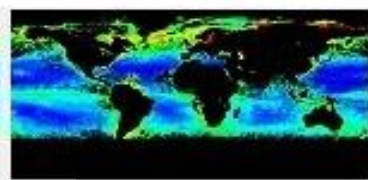

July 2010

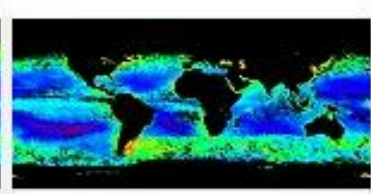

November 2012

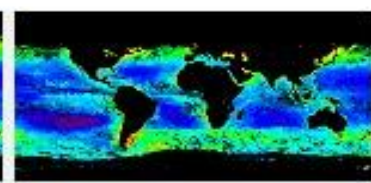

November 2015

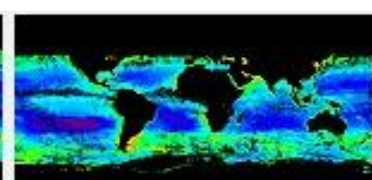

December 2002

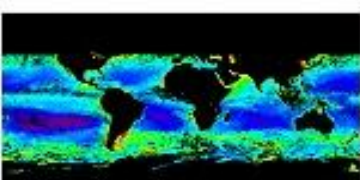

December 2003

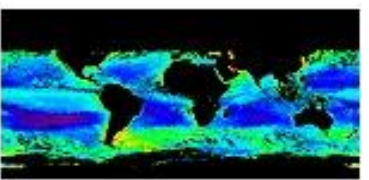

December 2008

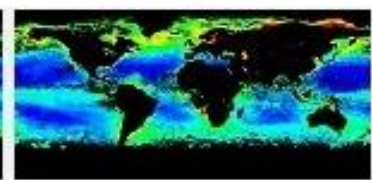

August 2010

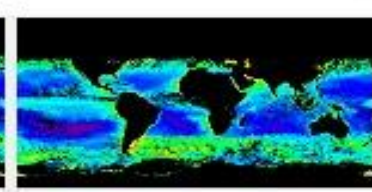

December 2012

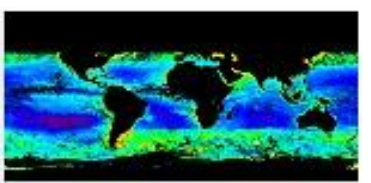

December 2015

Figure 2. Illustrating of some netCDF level 3 files on the NASA Ocean Color website (resolution $4 \mathrm{~km}$, Jully $2002 \div$ September 2018) 
In data quality control, we used two range checks on the chlorophyll_a data. The range check for chlorophyll a in the North Pacific, is $\left[0 \div 50 \mathrm{mg} / \mathrm{m}^{3}\right]$ according to World Ocean Database 2013 (Boyer et al., 2013), and the range check for chlorophyll $a$ in the Bien Dong (Southeast Asian Sea), is $\left[0 \div 20 \mathrm{mg} / \mathrm{m}^{3}\right]$ according to The oceanographic database of the South China Sea and adjacent waters (Vo et al., 2000). The results of data quality control are shown in Table 1.

Table 1 . The results of data quality control

\begin{tabular}{|c|c|c|c|}
\hline \multicolumn{4}{|c|}{ Sea surface chlorophyll a data in the SVNC } \\
\hline Range checks & $\begin{array}{c}\text { Total Chla } \\
\text { values }\end{array}$ & $\begin{array}{c}\text { Number of } \\
\text { values inside }\end{array}$ & $\begin{array}{c}\text { Good data } \\
(\%)\end{array}$ \\
\hline $\begin{array}{c}{[0 \div 50} \\
\left.\mathrm{mg} / \mathrm{m}^{3}\right]\end{array}$ & 229.230 & 229.169 & $99,97 \%$ \\
\hline $\begin{array}{c}{[0 \div 20} \\
\left.\mathrm{mg} / \mathrm{m}^{3}\right]\end{array}$ & 229.230 & 228.552 & $99,70 \%$ \\
\hline Note: - Minimum chlorophyll_a: $0.059174\left(\mathrm{mg} / \mathrm{m}^{3}\right)$ \\
\hline
\end{tabular}

The above results (Table 1) show that the chlorophyll_a values greater than $20\left[\mathrm{mg} / \mathrm{m}^{3}\right]$ are rare, and the chlorophyll a data estimated from the MODIS Aqua of US NASA are reasonable and very reliable. So, we decided to use the range check $\left[0 \div 20 \mathrm{mg} / \mathrm{m}^{3}\right]$ for the data quality control, and the data was outside the range check would be deleted. Thus, on average, each MODIS image file has about 1,172 sea surface chlorophyll a values evenly distributed in the SVNC. The study area and the spatial distribution of chlorophyll_a value points are described in Fig. 1.

In data analysis, we used Microsoft Access statistical functions to calculate the averaged chlorophyll_a concentration, which grouped by months, seasons and ENSO type years (Neutral, El Niño and La Niña years). The data were exported to Microsoft Excel files to build the graphs and charts describing the variation of chlorophyll_a concentration over time.

To determine the impact of ENSO phenomenon on sea surface chlorophyll_a concentration, we analyzed chlorophyll_a concentration anomaly (Chla anomaly) and compared with ONI values in the corresponding time. Chla anomaly is variability of monthly chlorophyll_a concentration in comparison with the 3-monthly averaged chlorophyll_a concentration, in which the calculation month is in the middle. For example, calculating Chla anomaly for July, then Chla anomaly will equal the average chlorophyll_a of July minus the average chlorophyll_a of group 3 months: June, July, and August. This is also the way to calculate the Oceanic Niño Index (ONI) to identify El Niño and La Niña events in the tropical Pacific. These events are defined as 5 consecutive overlapping 3-month periods at or above the $+0.5^{\circ} \mathrm{C}$ anomaly for warm (El Niño) events and at or below the $0.5^{\circ} \mathrm{C}$ anomaly for cold (La Niña) events. The threshold is further broken down into Weak (with a 0.5 to 0.9 SST anomaly), Moderate (1.0 to 1.4 ), Strong (1.5 to 1.9$)$ and Very Strong $(\geq 2.0)$ events (Golden Gate Weather Services, 2019).

\section{Results}

The calculated results of monthly averaged chlorophyll_a concentration in the SVNC are listed in Table 2. The analysis results of Chla anomaly in the SVNC are described in Table 3. Figure 3 is the graph describing the variation of Chla anomaly and ONI according to months in the SVNC.

In the SVNC, there are not fully four seasons as in north Vietnam. However, the study area is influenced by the flow of the Mekong river. The upper reaches of the Mekong River start from China and flow through the north of Vietnam (Kundan, 2016), where there are four distinct seasons. Besides, the SVNC is also affected by the southwest and northeast monsoon winds. The southwest monsoon wind occurs during summer months, and the northeast monsoon wind occurs during winter months. Therefore, in this study, we statistically calculate the average chlorophyll_a concentration by seasons. This result is described in Fig. 4. 
Vietnam Journal of Earth Sciences, 42(1), 67-79

Table 2. The calculation results of monthly averaged chlorophyll_a concentration $\left[\mathrm{mg} / \mathrm{m}^{3}\right]$ in the SVNC

\begin{tabular}{|c|c|c|c|c|c|c|c|c|c|c|c|c|c|c|c|}
\hline \multirow{3}{*}{$\begin{array}{c}\text { ENSO Type } \\
\text { ME } \\
\end{array}$} & \multirow{2}{*}{\multicolumn{3}{|c|}{ Season }} & \multicolumn{12}{|c|}{ MONTH } \\
\hline & & & & \multirow[t]{2}{*}{6} & \multirow{2}{*}{$\frac{7}{2.0}$} & \multirow{2}{*}{\begin{tabular}{|c|c|}
8 \\
2.3
\end{tabular}} & \multirow{2}{*}{\begin{tabular}{|c|}
9 \\
2.0
\end{tabular}} & \multirow{2}{*}{$\begin{array}{ll}10 \\
2.2 \\
\end{array}$} & \multirow{2}{*}{\begin{tabular}{|c|}
11 \\
3.0
\end{tabular}} & \multirow{2}{*}{$\frac{12}{2.2}$} & \multirow{2}{*}{\begin{tabular}{c|c}
1 \\
2.4
\end{tabular}} & \multirow{2}{*}{\begin{tabular}{c|c}
2 \\
1.9
\end{tabular}} & \multirow{2}{*}{\begin{tabular}{c|c}
3 \\
1.7
\end{tabular}} & \multirow{2}{*}{\begin{tabular}{c|c}
4 \\
1.7
\end{tabular}} & \multirow{2}{*}{\begin{tabular}{c|c}
5 \\
1.4
\end{tabular}} \\
\hline & 2002 & - & 2003 & & & & & & & & & & & & \\
\hline & 2003 & - & 2004 & 1.9 & 2.8 & 2.0 & 1.9 & 3.7 & 2.2 & 2.9 & 2.0 & 1.4 & 1.7 & 1.5 & 2.0 \\
\hline WE & 2004 & - & 2005 & 1.7 & 2.3 & 2.0 & 2.7 & 2.5 & 2.8 & 2.4 & 2.2 & 1.6 & 1.5 & 1.7 & 1.9 \\
\hline WL & 2005 & - & 2006 & 1.9 & 2.2 & 1.7 & 2.4 & 2.0 & 2.6 & 2.8 & 2.4 & 1.8 & 2.0 & 1.6 & 1.8 \\
\hline WE & 2006 & - & 2007 & 1.7 & 1.9 & 2.5 & 2.5 & 3.2 & 2.4 & 3.1 & 2.4 & 1.8 & 1.3 & 1.6 & 1.6 \\
\hline SL & 2007 & - & 2008 & 2.2 & 2.6 & 2.4 & 2.0 & 3.5 & 3.3 & 3.0 & 2.3 & 1.7 & 1.5 & 1.7 & 1.7 \\
\hline WL & 2008 & - & 2009 & 2.1 & 2.3 & 2.5 & 1.3 & 2.8 & 3.1 & 3.1 & 2.7 & 2.4 & 1.7 & 1.5 & 1.6 \\
\hline $\mathrm{ME}$ & 2009 & - & 2010 & 2.1 & 2.4 & 2.2 & 3.1 & 3.4 & 2.8 & 2.7 & 1.9 & 2.1 & 1.8 & 1.6 & 2.0 \\
\hline SL & 2010 & - & 2011 & 2.3 & 2.1 & 2.2 & 2.2 & 3.8 & 3.6 & 3.3 & 2.8 & 1.6 & 1.3 & 1.5 & 1.5 \\
\hline \multirow[t]{3}{*}{ ML } & 2011 & - & 2012 & 1.3 & 2.2 & 2.7 & 1.9 & 2.7 & 2.4 & 2.5 & 2.5 & 1.8 & 1.4 & 2.0 & 1.6 \\
\hline & 2012 & - & 2013 & 2.3 & 2.5 & 2.5 & 2.4 & 3.5 & 2.2 & 2.3 & 2.2 & 1.6 & 1.7 & 1.7 & 1.9 \\
\hline & 2013 & 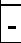 & 2014 & 2.0 & 2.0 & 2.5 & 2.2 & 2.2 & 2.4 & 2.2 & 2.6 & 2.3 & 1.9 & 2.1 & 2.4 \\
\hline WE & 2014 & - & 2015 & 1.8 & 2.3 & 2.7 & 2.8 & 3.8 & 2.7 & 3.1 & 2.5 & 2.4 & 1.7 & 1.8 & 2.1 \\
\hline VSE & 2015 & $\begin{array}{lll}- & \\
\end{array}$ & 2016 & 2.2 & 2.6 & 2.8 & 3.1 & 2.9 & 2.2 & 2.4 & 2.2 & 2.0 & 1.6 & 1.7 & 1.6 \\
\hline WL & 2016 & & 2017 & 2.0 & 2.8 & 1.6 & 1.4 & 1.9 & 3.2 & 2.8 & 2.0 & 2.4 & 1.8 & 2.3 & 2.2 \\
\hline \multirow[t]{2}{*}{ WL } & 2017 & - & 2018 & 2.1 & 2.1 & 2.7 & 2.3 & 2.3 & 2.3 & 3.3 & 2.6 & 2.1 & 1.5 & 1.8 & 2.2 \\
\hline & 2018 & & 2019 & 2.2 & 2.0 & 1.8 & 2.7 & & & & & & & & \\
\hline \multicolumn{16}{|c|}{$\begin{array}{l}\text { Averaged chlorophyll_a in the SVNC: } 2.23\left[\mathrm{mg} / \mathrm{m}^{3}\right] \\
\text { Monthly averaged variability of chlorophyll a in the SVNC: } \pm 0.22\left[\mathrm{mg} / \mathrm{m}^{3}\right]\end{array}$} \\
\hline
\end{tabular}

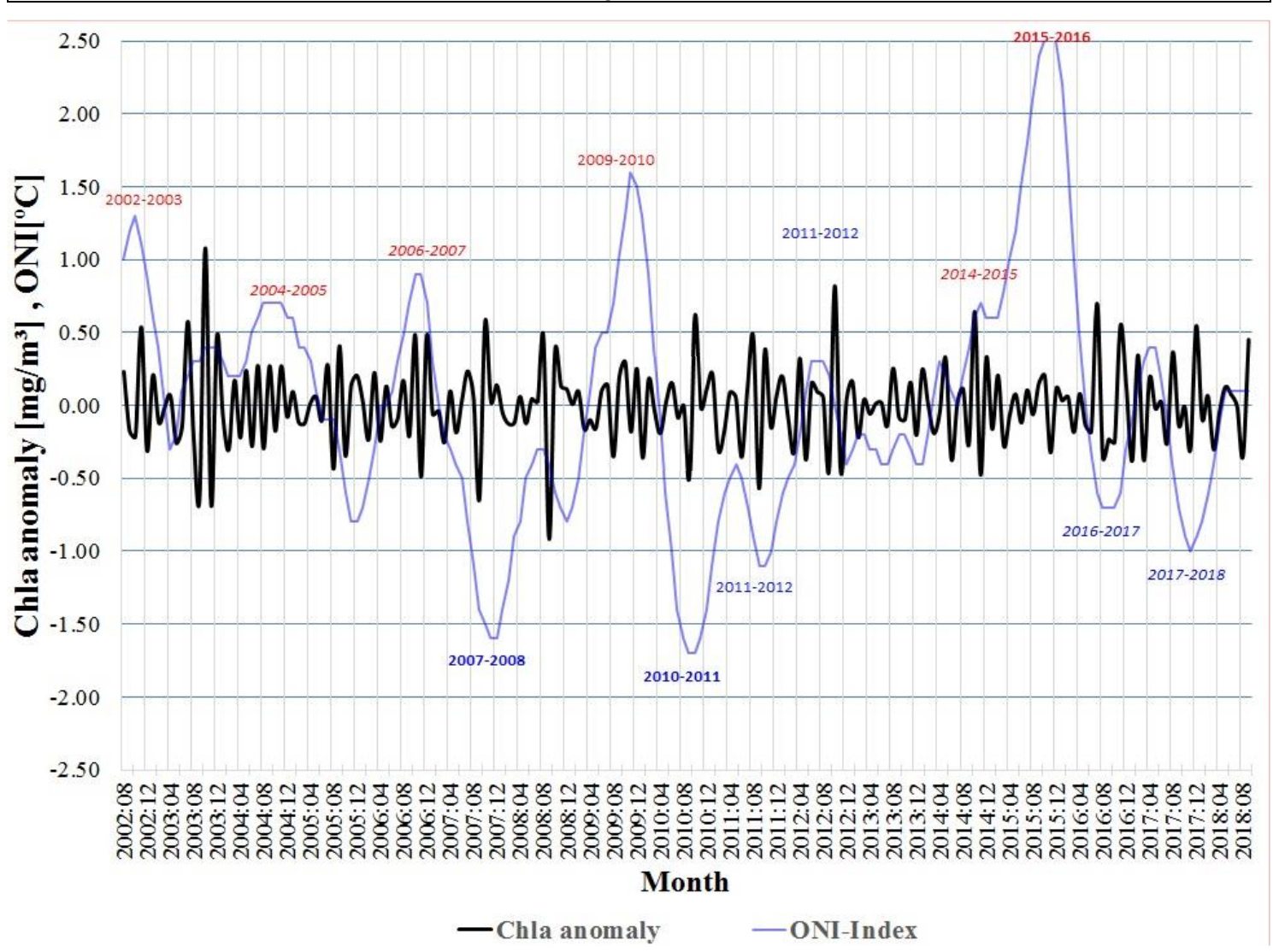

Figure 3. The variation of Chla anomaly and ONI according to months in the SVNC 
Vu Van Tac/Vietnam Journal of Earth Sciences 42(2020)

Table 3. The analysis results of Chla anomaly in the SVNC

\begin{tabular}{|c|c|c|c|c|c|c|c|c|c|c|c|c|c|c|}
\hline \multirow{3}{*}{$\begin{array}{c}\text { ENSO } \\
\text { Type } \\
\text { ME }\end{array}$} & \multirow{2}{*}{\multicolumn{2}{|c|}{ Season }} & \multicolumn{12}{|c|}{ MONTH } \\
\hline & & & \multirow[t]{2}{*}{6} & \multirow[t]{2}{*}{7} & \multirow{2}{*}{$\begin{array}{c}8 \\
0.2 \\
\end{array}$} & \multirow{2}{*}{$\begin{array}{c}9 \\
-0.2\end{array}$} & \multirow{2}{*}{$\begin{array}{c}10 \\
-0.2\end{array}$} & \multirow{2}{*}{$\begin{array}{c}11 \\
0.5\end{array}$} & \multirow{2}{*}{$\begin{array}{c}12 \\
-0.3\end{array}$} & \multirow{2}{*}{$\begin{array}{c}1 \\
0.2\end{array}$} & \multirow{2}{*}{$\begin{array}{c}2 \\
-0.1\end{array}$} & \multirow{2}{*}{$\begin{array}{c}3 \\
0.0 \\
\end{array}$} & \multirow{2}{*}{$\begin{array}{c}4 \\
0.1\end{array}$} & \multirow{2}{*}{$\begin{array}{c}5 \\
-0.3\end{array}$} \\
\hline & 2002 & 2003 & & & & & & & & & & & & \\
\hline & 2003 & 2004 & -0.1 & 0.6 & -0.2 & -0.6 & 1.1 & -0.7 & 0.5 & -0.1 & -0.3 & 0.2 & -0.2 & 0.2 \\
\hline WE & 2004 & 2005 & -0.3 & 0.3 & -0.3 & 0.3 & -0.2 & 0.3 & -0.1 & 0.1 & -0.1 & -0.1 & 0.0 & 0.1 \\
\hline WL & 2005 & 2006 & -0.1 & 0.3 & -0.4 & 0.4 & -0.3 & 0.1 & 0.2 & 0.0 & -0.2 & 0.2 & -0.2 & 0.1 \\
\hline WE & 2006 & 2007 & -0.1 & -0.1 & 0.2 & -0.2 & 0.5 & -0.5 & 0.5 & -0.1 & 0.0 & -0.3 & 0.1 & -0.2 \\
\hline SL & 2007 & 2008 & 0.0 & 0.2 & 0.1 & -0.6 & 0.6 & 0.0 & 0.1 & -0.1 & -0.1 & -0.1 & 0.1 & -0.1 \\
\hline WL & 2008 & 2009 & 0.0 & 0.0 & 0.5 & -0.9 & 0.4 & 0.1 & 0.1 & 0.0 & 0.1 & -0.2 & -0.1 & -0.2 \\
\hline $\mathrm{ME}$ & 2009 & 2010 & 0.1 & 0.1 & -0.3 & 0.2 & 0.3 & -0.2 & 0.3 & -0.4 & 0.2 & 0.0 & -0.2 & 0.0 \\
\hline SL & 2010 & 2011 & 0.2 & -0.1 & 0.0 & -0.5 & 0.6 & 0.0 & 0.1 & 0.2 & -0.3 & -0.2 & 0.1 & 0.1 \\
\hline ML & 2011 & 2012 & -0.4 & 0.1 & 0.5 & -0.6 & 0.4 & -0.1 & 0.1 & 0.2 & -0.1 & -0.3 & 0.3 & -0.4 \\
\hline & 2012 & 2013 & 0.2 & 0.1 & 0.1 & -0.4 & 0.8 & -0.5 & 0.0 & 0.2 & -0.2 & 0.0 & -0.1 & 0.0 \\
\hline & 2013 & 2014 & 0.0 & -0.1 & 0.3 & -0.1 & -0.1 & 0.2 & -0.2 & 0.2 & 0.0 & -0.2 & 0.0 & 0.3 \\
\hline WE & 2014 & 2015 & -0.4 & 0.0 & 0.1 & -0.3 & 0.6 & -0.5 & 0.3 & -0.2 & 0.2 & -0.3 & -0.1 & 0.1 \\
\hline VSE & 2015 & 2016 & -0.1 & 0.1 & -0.1 & 0.2 & 0.2 & -0.3 & 0.1 & 0.0 & 0.1 & -0.2 & 0.1 & -0.1 \\
\hline WL & 2016 & 2017 & -0.2 & 0.7 & -0.4 & -0.2 & -0.3 & 0.5 & 0.1 & -0.4 & 0.3 & -0.4 & 0.2 & 0.0 \\
\hline WL & 2017 & 2018 & 0.0 & -0.3 & 0.4 & -0.1 & 0.0 & -0.3 & 0.5 & -0.1 & 0.1 & -0.3 & 0.0 & 0.1 \\
\hline WL & 2018 & 2019 & 0.1 & 0.0 & -0.4 & 0.4 & & & & & & & & \\
\hline
\end{tabular}

ENSO Type: WE=Weak El Niño, ME=Moderate El Niño, SE=Strong El Niño, VSE=Very Strong El Niño

$\mathrm{WL}=$ Weak La Niña, ML=Moderate La Niña, $\mathrm{SL}=$ Strong La Niña

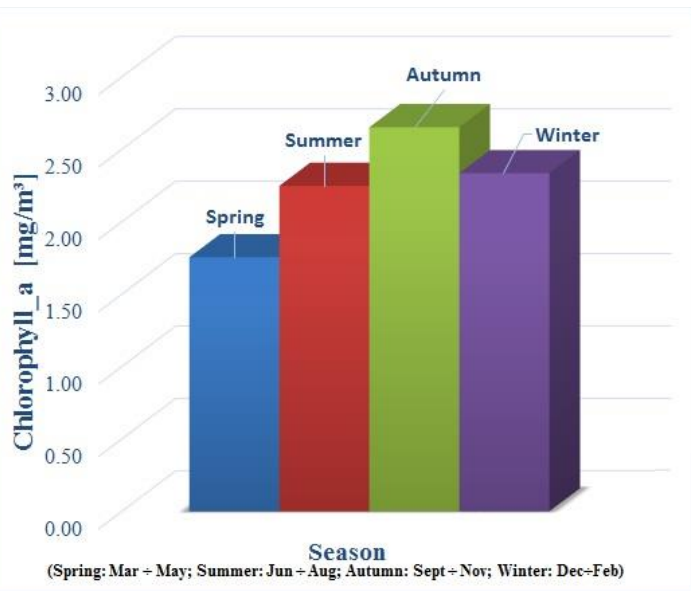

Figure 4. The seasonal average chlorophyll_a concentration $\left[\mathrm{mg} / \mathrm{m}^{3}\right]$ in the SVNC

Based on the calculations and analysis results described in Table 2, 3 and the graph and chart above (Fig. 3, 4) we have some comments as follows:

- Each occurrence of ENSO phenomenon greatly affects the fluctuation of chlorophyll_a concentration in the SVNC. The Chla anomaly values fluctuate in the range $(0.5 \div 1.1)$, while the mean chlorophyll_a concentration in the whole study area is $2.23\left[\mathrm{mg} / \mathrm{m}^{3}\right]$ and the monthly variability of chlorophyll_a concentration in the SVNC is only: $\pm 0.22\left[\mathrm{mg} / \mathrm{m}^{3}\right]$ (Table 2). These show that the range of Chla anomaly fluctuations $\left(0.5\left[\mathrm{mg} / \mathrm{m}^{3}\right] \div 1.1\left[\mathrm{mg} / \mathrm{m}^{3}\right]\right)$ is equivalent to the variation of the monthly averaged chlorophyll_a concentration corresponding to between $22.4 \%$ and $49.3 \%$. This proves that ENSO phenomenon has a great influence on chlorophyll_a concentration in the SVNC (the fluctuation of average chlorophyll_a concentration in months is only 9.88\%). Under the impact of ENSO phenomenon (usually occurring in December), Chla anomaly values usually exceed the \pm 0.5 thresholds in July and from September to November of the next year. This, combined with the analytical data in Table 3 , shows that the time of impact of ENSO on chlorophyll_a concentration in the SVNC is usually about 7 months later than the ONI (usually peak in December) and the affected time lasts from 5 to 6 months.

- The chlorophyll_a concentration in the SVNC always varies among seasons in the years (Fig. 3). The average chlorophyll_a 
concentration usually reaches its maximum value in the Autumn (Sep.-Nov), then decreases in the Winter (Dec.-Feb.) and usually reaches the minimum value in the Spring (Mar.-May), then rises gradually in the Summer (June-Aug.).

To find out more about the impact of ENSO phenomena on the chlorophyll_a concentration in the SVNC, we calculate monthly averaged chlorophyll_a in the whole study area for 5 months with the most fluctuation: July and from September to December. For the sake of comparison, the calculation months are grouped by El Niño, La Niña and Neutral years. The calculation results are described in Table 4 and Fig. 5.

Table 4. Monthly averaged chlorophyll_a concentration grouped by events of ENSO

\begin{tabular}{|c|c|c|c|}
\hline Month & Neutral years & El Niño years & La Niña years \\
\hline Jul & 2.14 & 2.58 & 2.29 \\
\hline Sept. & 2.46 & 2.22 & 2.42 \\
\hline Oct & 2.70 & 2.94 & 2.99 \\
\hline Nov & 2.75 & 2.78 & 2.50 \\
\hline Dec & 2.48 & 2.83 & 2.87 \\
\hline
\end{tabular}

Besides, based on the variation of Chla anomaly and ONI according to months in the SVNC (Fig. 3), we built distributions of monthly mean sea surface chlorophyll_a concentration in the SVNC in the periods which have the most fluctuating chlorophyll_a concentration (Fig. 3): Sep. $\div$ Dec. 2003 (Fig. 6), Aug. $\div$ Nov. 2008 (Fig. 7) and Sep. $\div$ Dec. 2012 (Fig. 8). These distributions were developed for the entire study area, including offshore areas to help readers have a visual view of the fluctuations of chlorophyll_a concentration in the SVNC. These

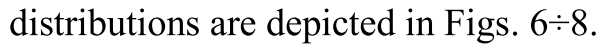

From the above results (Table 4 and Fig.5), we can see that under the impact of El Niño events the averaged chlorophyll_a concentration in July increased by 0.44 [mg/m $\left.\mathrm{m}^{3}\right]$ (equivalent to $20 \%$ ) compared to the Neutral and La Niña years. This concentration decreased $0.25\left[\mathrm{mg} / \mathrm{m}^{3]}\right.$ (equivalent to $11 \%$ ) in September. In addition, the averaged chlorophyll_a concentration increased by about $10 \div 13 \%$ in October and increased from $16 \div 18 \%$ in December in El Niño and La Niña years (compared to the Neutral years).

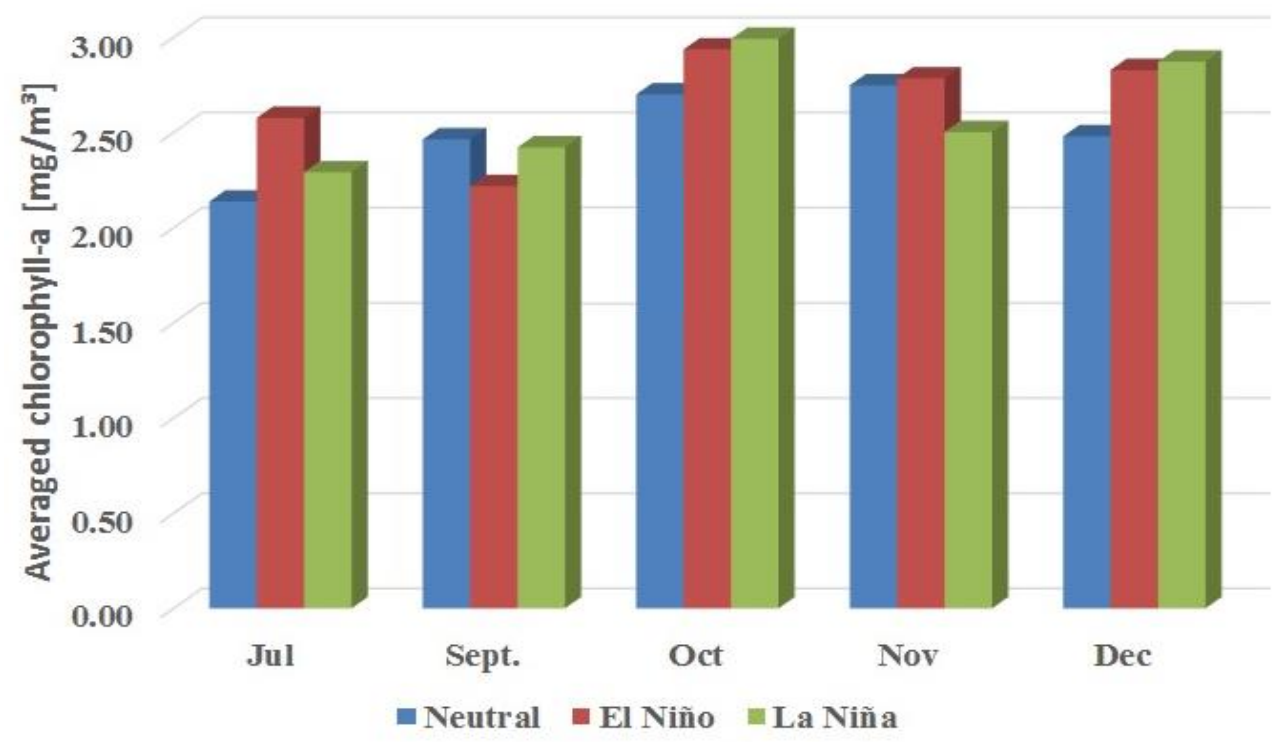

Figure 5. The monthly averaged chlorophyll_a concentration chart according to ENSO's Events 
Vu Van Tac/Vietnam Journal of Earth Sciences 42(2020)
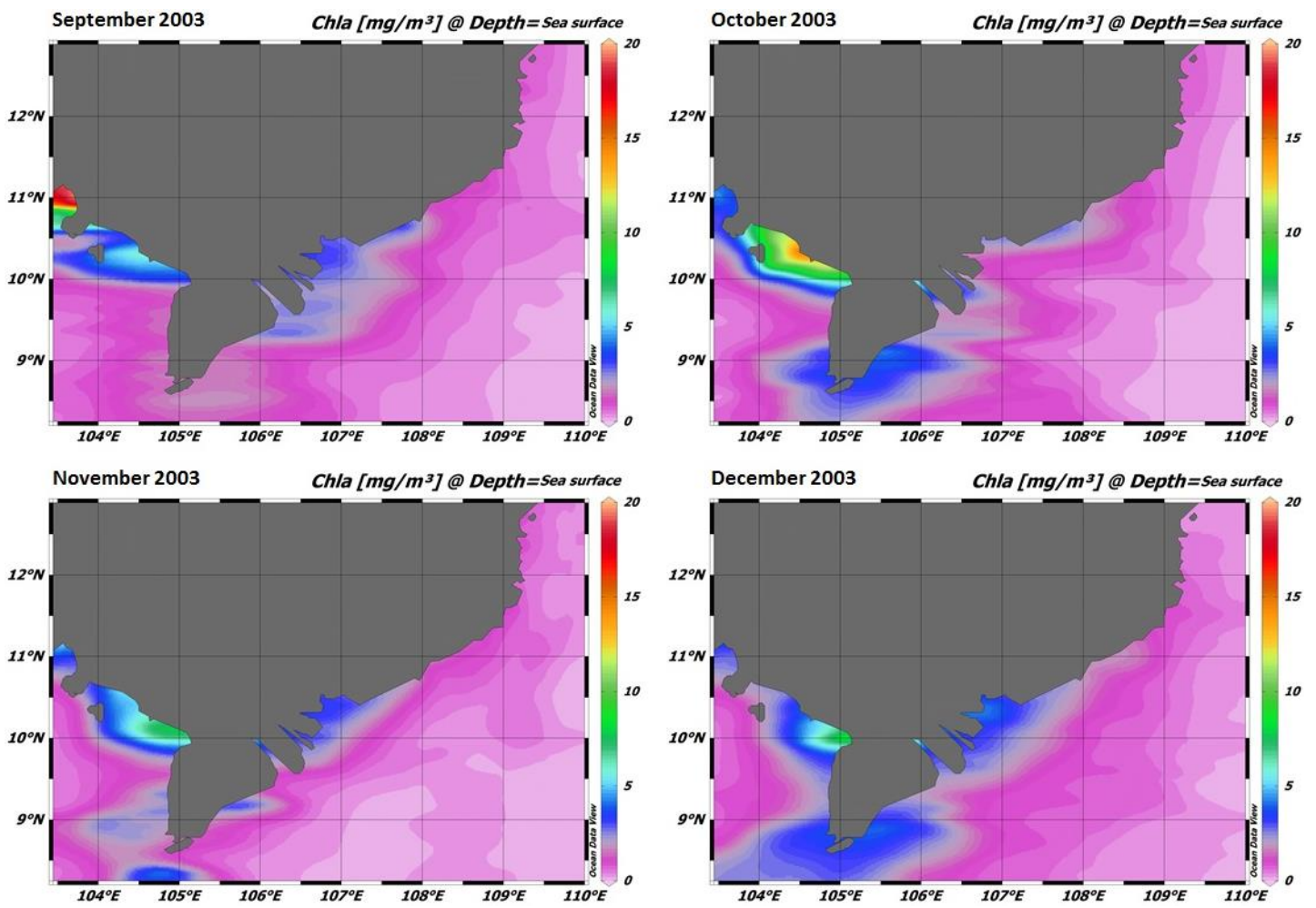

Figure 6. The mean sea surface chlorophyll a concentration distributions in the SVNC, Sep. $\div$ Dec. 2003
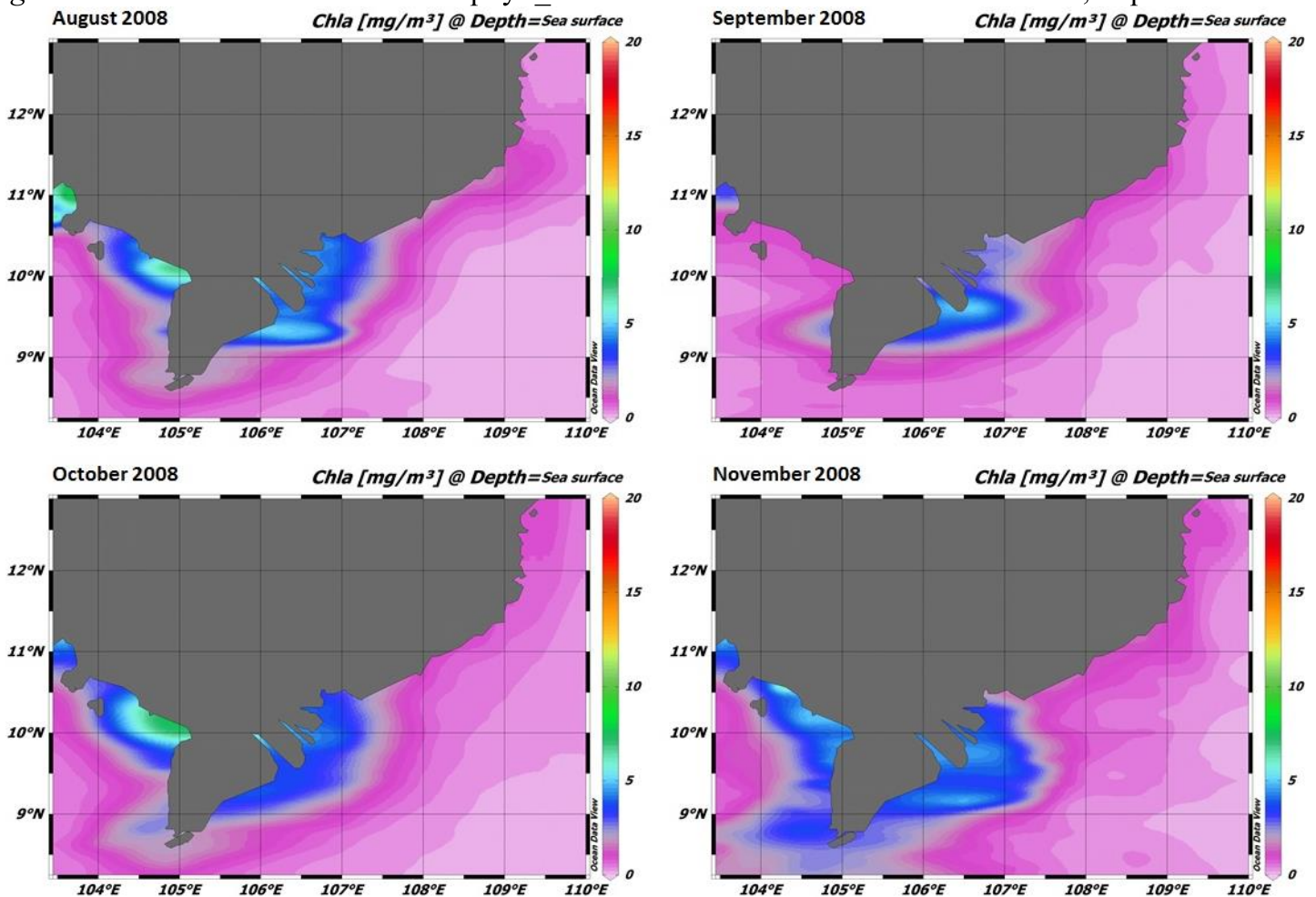

Figure 7. The mean sea surface chlorophyll_a concentration distributions in the SVNC, Aug. $\div$ Nov. 2008 

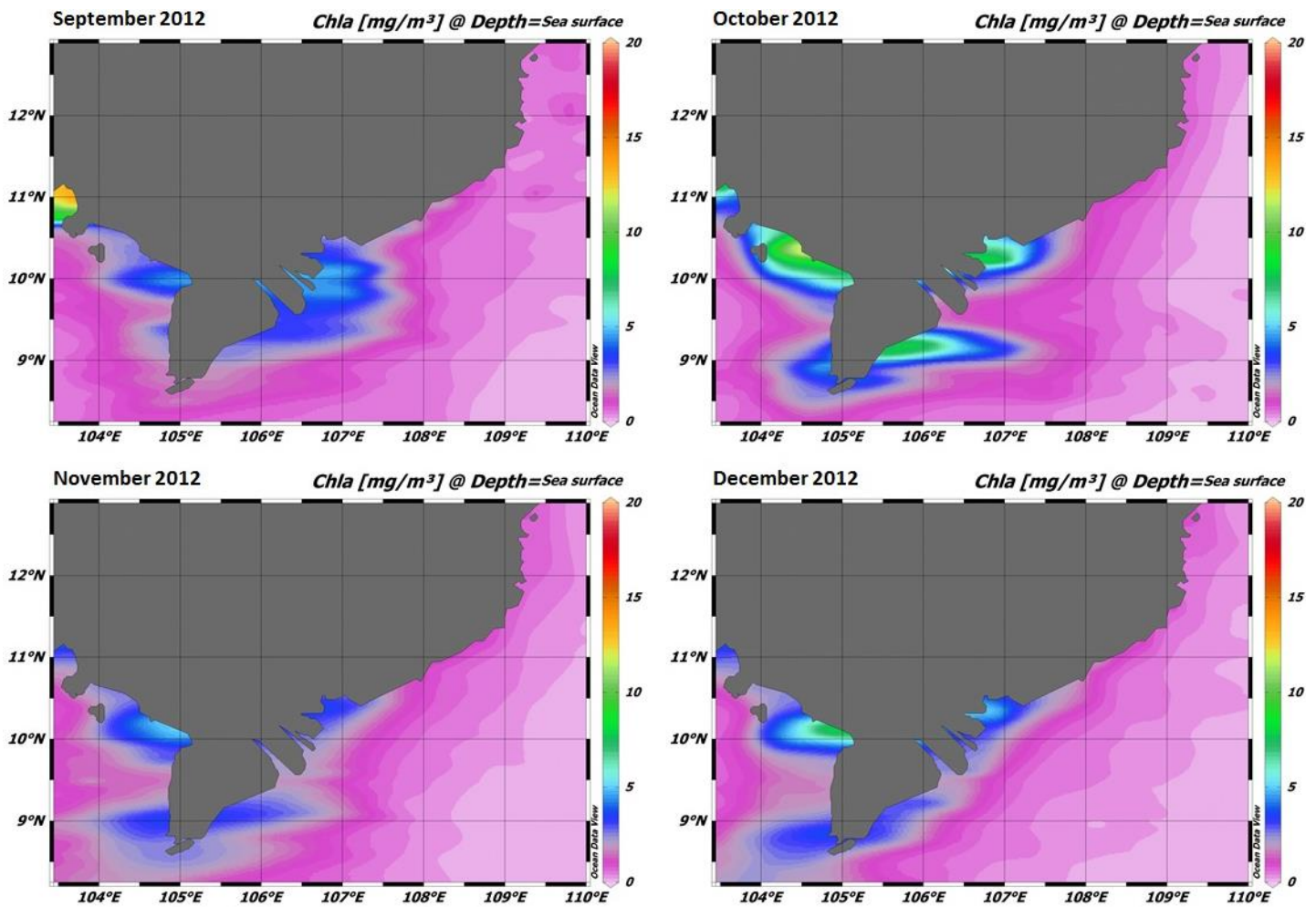

Figure 8. The mean sea surface chlorophyll_a concentration distributions in the SVNC, Sep. $\div$ Dec. 2012

\section{Discussions}

The above analysis results have partly described the relationship between ENSO events and the variability of chlorophyll_a concentration in the SVNC. However, the variability of chlorophyll_a concentration depends on many factors, such as temperature, rainfall, upwelling, wind, ocean currents, etc. Therefore, to explain in detail the causes of the variability at specific times requires more extensive research. However, with the result of the average chlorophyll_a concentration in July increased by $20 \%$ in El Niño years, it can be explained by the reason that in the El Niño years, the upwelling phenomenon is very strong in the Vietnam south central coast (Ninh Thuan, Binh Thuan provinces), and this phenomenon is often the most active in July (Bui et al., 2017). Upwelling is an oceanographic phenomenon that involves wind-driven motion of dense, cooler, and usually nutrient-rich water towards the ocean surface, replacing the warmer, usually nutrient-depleted surface water (NOAA website, 2019). This phenomenon increases the chlorophyll_a concentration of the sea surface layer.

The result of the average chlorophyll_a concentration in July increased by $20 \%$ in El Niño years, is also quite similar to the results of the analysis "The impact of regional chlorophyll-anomaly in the Arafura Sea" with the conclusion: The highest chlorophyll-a concentration $\left(>1\left[\mathrm{mg} / \mathrm{m}^{3}\right]\right)$ occurred during Niño and observed around the Aru archipelago (Dewi et al., 2018).

Also, with statistical results: The average chlorophyll_a concentration usually reaches its maximum value in the Autumn, then decreases in the Winter and usually reaches the minimum value in the Spring, then rises gradually in the Summer. This result is quite 
similar to the result we have calculated in the coastal marine area of Vietnam South Center (Vu et al., 2018). However, the fluctuations of Chlorophyll-a concentration between months in the SVNC is greater than that in the coastal marine area of Vietnam South Center. The Chla anomaly values in the coastal marine area of Vietnam South Center fluctuate in the range $\left(0.5\left[\mathrm{mg} / \mathrm{m}^{3}\right] \div 0.87\left[\mathrm{mg} / \mathrm{m}^{3}\right]\right)$ while the fluctuation range in the SVNC is $\left(0.5\left[\mathrm{mg} / \mathrm{m}^{3}\right] \div 1.1\left[\mathrm{mg} / \mathrm{m}^{3}\right]\right)$.

\section{Conclusions}

Summarizing the calculation and analysis results mentioned above, we draw some conclusions as follows:

- Each occurrence of the ENSO phenomenon greatly affects the fluctuation of chlorophyll a concentration in the SVNC. The averaged chlorophyll a concentration varies from $22.4 \%$ to $49.3 \%$, while the average fluctuation of chlorophyll_a concentration between months is only $9.88 \%$. This has a great impact on nutritional resources as well as water quality because chlorophyll a is a pigment in plankton, which is a criterion to assess the "rich or poor" of nutrition source in seawater.

- Under the impact of the ENSO phenomenon (usually occurring in December), Chla anomaly values usually exceed the \pm 0.5 thresholds in July and from September to November of the next year. This shows that the time of impact of ENSO on chlorophyll_a concentration in the SVNC is usually about 7 months later than the ONI and the affected time lasts from 5 to 6 months.

- In the El Niño years, the averaged chlorophyll_a concentration in July increased by $20 \%$ in comparison to the Neutral and La Niña years. This concentration decreased by $11 \%$ in September. Also, the averaged chlorophyll a concentration increased by about $10 \div 1 \overline{3} \%$ in October and increased from $16 \div 18 \%$ in December in El Niño and La Niña years (compared to the Neutral years).
- The chlorophyll_a concentration in the SVNC always varies among seasons in the years. The averaged chlorophyll_a concentration usually reaches its maximum value in the Autumn, then decreases in the Winter and usually reaches the minimum value in the Spring, then rises gradually again in the Summer.

The above research results contribute to improving the understanding of the impact of the ENSO phenomenon on the SVNC, supported scientists and managers in proposing measures to prevent, avoid efficiently, limit and mitigate the damage caused by ENSO, and having reasonable alternatives in the protection of biodiversity as well as the environment in the SVNC. It could be considered as a "small part" of the overall picture of the impacts of the ENSO phenomenon on global climate change.

\section{References}

Boyer T.P., Antonov J.I., Baranova O.K., Coleman C., Garcia H.E., Grodsky A., Johnson D.R., Locarnini R.A., Mishonov A.V., O'Brien T.D., Paver C.R., Reagan J.R., Seidov D., Smolyar I.V., Zweng M.M., 2013, World Ocean Database 2013. Sydney Levitus, Ed.; Alexey Mishonov, Technical Ed.; NOAA Atlas NESDIS, 72, 209p.

Bui Hong Long, Tran Van Chung, 2017, Preliminary studies on the impact of climate change on the upwelling phenomenon in south central Vietnam waters in summer, Journal of Marine Science and Technology, 17(1), 1-11, Doi: 10.15625/18593097/17/1/9716. http://www.vjs.ac.vn/index.php/jmst.

Dewi D.M.P.R., Fatmasari D., Kurniawan A., Munandar M.A., 2018. The impact of ENSO on regional chlorophyll-a anomaly in the Arafura Sea. In IOP Conference Series: Earth and Environmental Science, 139(1), 012020.

David Eckstein, Vera Künzel, Laura Schäfer L., 2017. Global Climate Risk Index 2018. ISBN978-3-943704-60-0. Available at www.germanwatch.org/de/14638 (16 Nov 2018).

Dham Khalila, Peter M. Atkinsona, Peter Challenorc, 2016. Historical and future trends in seasurface 
Vietnam Journal of Earth Sciences, 42(1), 67-79

temperature (SST) in the Indo-Pacific region from 1982 to 2100, International Journal of Applied Earth Observation and Geoinformation, 45, 14-26.

Dilley M, N Heyman B., 1995. ENSO and disaster: droughts, floods and El Nino/Southern Oscillation warm events. Disasters., 19, 181-193.

Domeisen D.I.V., Garfinkel C.I., Butler A.H., 2019. Global impacts of ENSO's reach into the stratosphere, Eos, 100. https://doi.org/10.1029/2019EO115943. Published on 19 February 2019.

Golden Gate Weather Services, Updated thru Nov-DecJan 2018-2019. El Niño and La Niña Years and Intensities: http://ggweather.com/enso/oni.htm.

Kahru M., Di Lorenzo E., Manzano-Sarabia M, Mitchell BG. 2012. Spatial and temporal statistics of sea surface temperature and chlorophyll fronts in the California Current. Journal of Plankton Researchm, 34, 749-760.

Kundan Kumar Sagar, 2016. The Mekong River: Tracing the Journey from "Mother of Water" to 'Arena of Dams and Impending Disasters. Imperial Journal of Interdisciplinary Research (IJIR), 2(10), ISSN: 2454-1362, http://www.onlinejournal.in.

NASA Goddard Space Flight Center, Ocean Ecology Laboratory, Ocean Biology Processing Group. Moderate-resolution Imaging Spectroradiometer (MODIS) Aqua Chlorophyll Data; 2018 Reprocessing. NASA OB.DAAC, Greenbelt, MD, USA. Doi: 10.5067/AQUA/MODIS/L3B/CHL/2018. Accessed on 02/12/2018.

National Research Council, 1996. Learning to Predict Climate Variations Associated with El Nino and the Southern Oscillation: Accomplishments and Legacies of the TOGA Program. Washington, DC: The National Academies Press. https://doi.org/10.17226/5003.

NOAA. What is upwelling? National Ocean Service website,

https://oceanservice.noaa.gov/facts/upwelling.html, 19/03/19.

Vu T.V., Nguyen H.T., Nguyen T.V., Nguyen H.V., Pham H.T.T., Nguyen L.T., 2015. Effects of ENSO on autumn rainfall in Central Vietnam, Advances in Meteorology, Article ID 264373, 12p., https://doi.org/10.1155/2015/264373.

The National Aeronautics and Space Administration (NASA) Ocean Color website https://oceancolor.gsfc.nasa.gov/.

Tong Phuoc Hoang Son, Tran Van Chung, Nguyen Huu Huan, Ngo Manh Tien, Vu Van Tac, Nguyen Hoang Thai Khang, Nguyen Truong Thanh Hoi, Marine Herrmann, Eko Siswanto, 2017. Abnormal features of oceanographic characteristics in upwelling Vietnam waters under impact of El Niño events, Vietnam J. of Earth Sciences, 39(3), 225-239. Doi: $10.15625 / 0866-7187 / 39 / 3 / 10268$.

Tran Duc Thanh, 2015. Discussion on coastal zoning in Vietnam, Vietnam Journal of Earth Sciences, 15(1), 1-12. Doi: 10.15625/1859-3097/15/1/4155.

http://www.vjs.ac.vn/index.php/jmst

Vo Van Lanh, Phan Quang, Vu Van Tac, Lau Va Khin, Ngo Manh Tien, Dang Ngoc Thanh, 2000. The oceanographic database of the South China Sea and adjacent waters-Collection of Marine Research Works. Science And Technique Publishing House, 10, 254-259.

Vu Van Tac, Doan Nhu Hai, 2018, Chlorophyll concentration anomaly in Vietnam south central coast related to ENSO phenomenon. Journal of Marine Science and Technology, 18(1), 70-78. Doi: 10.15625/1859-3097/18/1/8786.

http://www.vjs.ac.vn/index.php/jmst.

Liu X., Wang J., Cheng X., Du Y., 2012. Abnormal upwelling and chlorophyll-a concentration off South Vietnam in summer 2007. Journal of Geophysical Research: Oceans, 117(C7).

Ward P.J., Kummu M., Lall U., 2016. Flood frequencies and durations and their response to El Niño Southern Oscillation: Global analysis. Journal of Hydrology, 539, 358-378. Doi: 10.1016/j.jhydrol.2016.05.045.

WMO 2014 El Niño-Southern Oscillation (Geneva: World Meteorology Organization), 2-8. WMO-No. 1145, ISBN 978-92-63-11145-6. Available online: http://library.wmo.int/pmb_ged/wmo_1145_en.pdf. 